\title{
UM EMPRESÁRIO DE ÍNICIO DE SÉCULO - - O POLÉMICO FABRICANTE DE ADUBOS DA ORTIGOSA (LEIRIA)
}

\author{
Alda Mourão Filipe* \\ Nos primeiros anos da República, o país assistia a uma fase da \\ intervenção do governo, tendente a valorizar, rendibilizar e modernizar a \\ tarefa dos agricultores portugueses. Incrementava-se a aplicação de \\ fertilizantes, ao mesmo tempo que se alertava para os falsos produtos que, \\ com esta designação, surgiam no mercado. \\ Ao longo de 1914, a imprensa de Leiria fez eco do problema que se \\ colocava a nivel nacional e que, na região, atingia personalidades \\ destacadas. \\ Acompanhámos a construção de um "Império", à dimensão local, que \\ passou pelo fabrico de adubos. Principalmente, tivemos um pretexto para \\ conhecer o evoluir de um empresário.
}

\section{INTRODUÇÃO}

Mediante toda uma complexa rede de polémica pública, destacámos um empresário local.

Acompanhar o seu percurso levar-nos-á a questionar se não estaremos perante o empresário definido à medida duma economia regional, mas que, com todas as capacidades de homem empreendedor no mundo dos negócios, vai tentar ultrapassar os limites da sua área de intervenção económica.

Importa então introduzir três grandes questões:

* Instituto Politécnico de Leiria, Escola Superior de Educação. 
1. Poder-se-á definir um perfil de empresário local?

2. É teoricamente correcto integrá-lo em modelos ou tipologias mais abrangentes?

Daqui decorre a terceira grande dúvida:

3. Existem modelos organizativos alheios às realidades locais de carácter estrutural, e mesmo conjuntural, aceitáveis para melhor analisar esta personagem?

Os primeiros óbices ao discurso científico produzido sobre este agente económico são precocemente detectados, perante as dificuldades oferecidas pela falta de rigor e de coerência, quando confrontados com as terminologias encontradas e os dúbios conceitos que abarcam. Isto é, as mesmas designações, decorrentes de fontes diversas, cobrem (ou podem cobrir) realidades algo distintas.

Pelo mesmo princípio, diferentes terminologias, identificadas num mesmo tipo de fontes, podem ser exactamente aplicadas às mesmas situações.

O quadro real em que nos passamos a mover apresenta-se, assim, com contornos complexos que tenderão a simplificar-se pela aplicação de processos analógicos já utilizados por investigadores da especialidade e, obviamente, pela análise de conteúdo dos diferentes tipos de informação/documentação disponíveis.

Importa alertarmos para as designações com que passamos a trabalhar e que implicam os vocábulos industrial, fabricante e empresário. Aparentemente são diferenciados entre si, mas veremos que, na verdade, são aplicáveis a realidades que, por vezes, se sobrepõem e coincidem. Esta vai ser uma das tarefas introdutórias que nos propomos desenvolver.

Mas deverá ser ainda considerada a clarificação das realidades designadas por fábrica e oficina: que evolução se processou? Que modelos comportaram?

Teremos ainda de nos precaver contra as realidades genericamente identificadas como indústria: como caracterizá-la, como dimensioná-la, como detectar evoluções?

Finalmente, como reconhecer localmente as unidades a que se reporta $\mathrm{e}$ que nos permitem inferir dum determinado tipo de industrialização? Este será objectivo a concretizar mais adiante - assim o esperamos - com o avançar de um estudo alargado sobre alguns aspectos da região económica de Leiria. 
O desafio apresentado por esta área de investigação parte, assim, de todo um conjunto de necessidades tendentes a clarificar os contextos reais com que nos deparamos e, simultaneamente, do quadro teórico a que temos de lançar mão. Nem sempre o diálogo se apresenta fácil, mas é, quase sempre, muito aliciante.

Identificados os problemas teóricos que tentámos desbravar, não podemos ser exaustivos neste momento, dada a fase em que se encontra a nossa investigação**.

Para já é nossa certeza de que não há modelos ou tipologias aplicáveis sem tomar em consideração as estruturas nacionais e locais. Serão elas, e as conjunturas que as vão integrando, que definirão as realidades em estudo que, mesmo reportadas a um espaço económico restrito, nem sempre manifestam coerência interna. Isto é, mesmo considerando uma micro-história, a heterogeneidade do sistema ajuda-nos a afastar a tentação de aplicar modelos tipológicos que representariam a simplificação da análise do objecto de estudo, mas que, por certo, distorceriam as realidades a conhecer.

\section{O REAL SIGNIFICADO DOS CONCEITOS}

Apresenta-se como metodologicamente correcto o dar uma particular atenção aos conceitos que passarão a dominar todo o ambiente respeitante ao tema a desenvolver. Na verdade, seria embaraçoso, se não mesmo enganador, não permitir que levantássemos em conjunto a problemática que decorre do real significado que era abarcado, ainda nos primeiros anos do séc. XX, pelas designações de indústria, fábrica e industrial.

Assim, por indústria entendia-se ainda globalmente qualquer actividade de que decorresse transformação de matérias-primas, tendo em vista um consumo próximo.

O espectro, assim generalizado, englobava desde as actividades processadas individual ou familiarmente, por vezes sem execução num espaço criteriosamente definido, recorrendo a processos de transformação exclusivamente manuais, até às actividades transformadoras que decorriam em sistemas organizativos mais complexos, utilizando diversos tipos de energias ${ }^{1}$.

Deste entendimento, que é patente na área económica de Leiria, ainda nos inícios do presente século, deriva uma mesma diversidade para o que era designado por fábrica. Esta vai tornar-se algo mais complexo do que simples unidade de produção, definida segundo parâmetros de caracterização claros, que passa pelos índices de produção, de consumo de energia, de 
equipamento, de capital e níveis de investimento, mas também pelo número de operários, condições de trabalho, estruturas sociais ... No período a que nos reportamos, a designação de fábrica era aplicada a realidades bem distintas entre si, que podiam ir da Real Fábrica de Vidros da Marinha Grande, à "fábrica" de fósforos da Ortigosa, de que mais adiante se dará conta.

A complexidade da estrutura ir-se-á construindo, num percurso já iniciado em finais de Oitocentos.

Das realidades anteriormente descritas, surge o indivíduo responsável pela produção - o industrial. Se, também neste domínio, nos reportarmos ao modelo inglês, o nosso desfasamento era considerável. Ultrapassando considerações diversas que nos são trazidas de vários domínios incluindo a própria literatura, a questão clarifica-se pela vulgarização da designação de "fabricante" que, para o caso que iremos conhecer, se aplica com muita correcção de significado, uma vez que, sob o ponto de vista conceptual, respeita a um nível de produtor distante do industrial, responsável por unidades de produção com escalas distintas ${ }^{2}$.

\section{A REALIDADE INDUSTRIAL}

Nas regiões menos desenvolvidas da Europa, é aceite ter-se verificado um período de desenvolvimento industrial até aos inícios da I Grande Guerra, mais concretamente entre 1870 e $1913^{3}$. No caso português, este desenvolvimento verificou-se lentamente, para além de ter sido, de facto, tardio. No plano político, as razões vão buscar-se ainda às invasões napoleónicas, aos primeiros anos do Liberalismo, à negligência sobre a exploração ultramarina; no plano económico, à pobreza do subsolo, à falta de capitais e de mercado, à concorrência estrangeira, à forte tradição agrícola. No social, à falta de uma burguesia dinâmica, arrojada para se entregar a novos planos, fundamentados em bens, que não os oriundos da terra. No plano cultural, manifestavam-se as grandes carências a nível do ensino e da formação.

Os têxteis, os tabacos, as moagens e os fertilizantes químicos vão distinguir-se no panorama industrial português, como sectores de produção que evidenciaram uma evolução muito positiva. De entre eles, saliento o que nos interessa no momento: os fertilizantes para uso agrícola que encontraram, localmente, condições para o seu desenvolvimento.

À região de Leiria são tradicionalmente reconhecidas as riquezas do subsolo. Para além da diversidade da sua natureza (que incluem gesso, ferro, 
lenhite, carvão de pedra, ocre, cal, a que se acrescentam os desejados ouro, prata e petróleo), recorde-se a procura que foi movida, quer por residentes, quer por forasteiros. Dirigiam-se à Câmara Municipal de Leiria, a fim de obterem concessão de licenças para proceder a explorações, vindos de Lisboa ou do Porto. Assim, tudo nos aponta para o reconhecimento desse "valor acrescentado" no âmbito da economia local. A este propósito, é de tomar em consideração a presença, entre os interessados, de companhias e sociedades nacionais ${ }^{4}$ e mesmo de estrangeiros ${ }^{5}$. É de dar uma especial atenção às figuras locais que se vão afirmando neste mundo da exploração do subsolo.

\section{UM EMPRESÁRIO LOCAL}

Vamos então fixar-nos na nossa proposta de trabalho: conhecer 0 percurso de um empresário local, originário e interveniente numa freguesia rural do concelho de Leiria.

Era comerciante de reconhecida importância, filho de indivíduo igualmente ligado a este sector, bem como ao do fabrico de fósforos. Atento às dinâmicas regionais que a economia nacional proporcionava, conduziu o seu percurso comercial de forma a acumular uma outra actividade: a industrial. Assim, vamos conhecer o seu espírito empreendedor, que arrisca capital e mesmo prestígio social numa "indústria" prometedora, porque recente e directamente ligada ao sector agrícola: começou então a fabricar adubos.

Por que lhe reconhecemos a designação de empresário?

Destacou-se entre a massa potencialmente geradora de movimentos propulsores da evolução económica, recorrendo à descrição e até à marginalidade da opinião pública, enquanto crescia e se estabelecia socialmente, para evoluir para o centro da polémica jornalística, numa posição de prestígio que, por isso mesmo, viria a deixar suspeita no que concerne à justeza do desfecho final do processo.

Surge assim “ o homem de negócio" que encerra uma tripla função: económica, social e psicológica. Apresentou-se como um modelo a seguir, para uns, e a evitar, para outros. Parece tratar-se do indivíduo pensado por Werner Plum, quando se referiu ao empresário, num processo de dinâmica capitalista:

Opera com novos produtos, novas técnicas de elaboração, novos procedimentos de política de venda, novas formas de organização e financiamento que, com frequência, cria novos sectores de produção ${ }^{6}$. 


\subsection{A fase dinâmica de construção de um espaço económico}

Em 1888 surge na vida económica da região leiriense Manuel da Silva Pereira, apresentando-se então a liderar um conjunto de contratos que visavam proporcionar-lhe adquirir ocre e gesso na freguesia do Souto da Carpalhosa. No ano seguinte, associa-se a um comerciante e proprietário da Marinha Grande, para constituir uma fábrica de laboração de ocre, que perdurará até Julho de 1891, momento em que é revogado o contrato, passando então Manuel da Silva Pereira a laborar sozinho. Ascende nesse momento à categoria profissional de "industrial", desconhecendo nós se por indicação do próprio, ou por promoção estatutária do notário que redigiu a escritura.

Em 1890 alarga a sua área de interesses, passando à exploração do minério e alargando, simultaneamente, o seu espaço de intervenção à freguesia de Az6ia, onde procedeu ao arrendamento de terras identificadas como ricas em ocre. Passa de imediato à exploração intensiva, construindo, para tanto, uma casa de madeira, no Alto do Vieiro, para aí fabricar ocre. Promovida à designação de fábrica, esta construção e os objectos usados na laboração são postos à venda no ano seguinte. Tudo seria vendido a quem mais desse.

Escolheu o jornal como forma de divulgação das suas intenções, permitindo-nos conhecer os meios de produção de que dispunha:

2 galgas de pedra lioz, 1 peneiro de metal amarelo, 8 picaretas de ferro, 8 pares de ferros, 1 funil de cobre, 1 funil de zinco, 1 balança decimal, 6 alavancas de ferro, 6 calcadeiras de ferro, 4 pedras de lioz, 1 vergalhão de ferro, 1 rodo de ferro, 6 carrinhos, 1000 sacos de grossaria da melhor qualidade. Além destes há outros muitos objectos pertencentes à mesma fábrica que também se vendem ${ }^{8}$.

A análise deste conjunto leva-nos a equacionar os valores do investimento exigido por esta produção. Na realidade, apresentava-se como muito limitada, no que respeita à diversidade de elementos, bem como à quantidade dos mesmos. Era uma unidade de muito pequena dimensão, quer no seu âmbito, sugerindo uma mão-de-obra que não ultrapassaria os 2-3 operários, quer no que respeita à tecnologia aplicada.

Apesar de pouco distarem entre si, as freguesias de Azóia e de Souto da Carpalhosa, tornar-se-ia difícil o controlo desta actividade fabril, quando mantida em simultâneo com o estabelecimento comercial na Ortigosa onde, aliás, residia. Poderá ter sido esse o entrave colocado à prossecução deste empreendimento. Nenhuma justificação era avançada. 
Mas, em 1894, a sua capacidade empreendedora manifesta-se com a aquisição, por trespasse, de uma outra "fábrica" na Ortigosa, desta vez de fósforos. $\mathrm{O}$ anterior proprietário era o seu pai, indiciando uma transmissão não só de bens, mas igualmente de "vivência empresarial", independentemente da amplitude do estabelecimento em causa.

Se o valor da aquisição (256 900 réis) indicava já a presença de uma pequena unidade transformadora, à qual a designação "fábrica" não deixava de ser acto de ostentação, a objectividade desta avaliação concretiza-se quando passamos a conhecer o recheio que encerra:

6 latas de massa fosfórica, 200 arrobas de enxofre, 400 quilos de papel para caixas, 100 quilos de papel para embrulhos, 4 ferros de rachar, 3 tachos de arame, 1 prato de folha para moldar, 6 mesas toscas grandes, 2 mesas pequenas, 2 fornos, 1 fornalha, 1 serra de mão, 1 serra braçal, 1 balança. ${ }^{9}$

Por uma eventual carência de capital, o que desconhecemos, em $1896 \mathrm{faz}$ uma primeira sociedade, para preparar ocre, e uma segunda para explorar e vender gesso ou barro, existente numa propriedade da freguesia do Souto da Carpalhosa. A primeira integra outros dois sócios, apresentando-se cada um como proprietário de fábricas para preparar ocre, ambas sitas nas Picotas, lugar da mesma freguesia. Se, por um lado, nos é permitido inferir da riqueza do subsolo da freguesia do Souto da Carpalhosa, também nos é lícito avançar a ideia de que o dinamismo dos locais é assinalável: organizam pequenos empreendimentos com matéria-prima local, num período favorável à aquisição do produto que lançam no mercado. Mais ainda: por uma estratégia de competitividade, associam-se no sentido de melhor rendibilizar a sua iniciativa, aumentando consequentemente os lucros.

Assim, a sociedade é feita por noventa anos, criando um depósito de ocre próximo da Estação de Caminho de Ferro de Monte Real, no sentido de ter melhores acessos a um mercado nacional ou, indo mais longe, de exportar, se thes convier. Na verdade, é de registar a diversidade de preços por saco de $15 \mathrm{Kg}$, quer se destine a Lisboa (240 réis), Porto (260 réis) ou ao resto do país (300 réis), admitindo dificuldades de comunicação igualmente distintas entre si.

Mas o documento, base da constituição desta sociedade, é mais rico de informação, quando passa a estipular quais serão os objectivos industriais a concretizar em tempo não especificado: se vierem a construir uma fábrica para ocre lavado, o valor da construção, bem como da compra de terrenos, máquinas, engenhos e utensílios ficará à conta da sociedade. 
O documento é ainda tanto mais interessante quanto o seu conteúdo alude a claras regras de mercado: perante a concorrência de produtos estrangeiros, é prevista uma descida de preço por saco desta produção local, que pode ir até aos $100 \mathrm{réis} / 15 \mathrm{Kg}$.

No mesmo dia da redaç̧ão deste documento, 25 de Agosto de 1896, Manuel da Silva Pereira e um outro elemento desta empresa fazem uma outra sociedade, agora com dois proprietários da Ortigosa, para garantirem todo o gesso ou barro que existia num prazo de que estes últimos eram enfiteutas. Os lucros dividir-se-iam entre os dois sócios do primeiro agrupamento, que pagavam aos segundos desta segunda sociedade 50 réis por cada tonelada de gesso. Garantia-se a matéria- prima para a laboração!

Decorridos cerca de dois anos, em 1898, Manuel da Silva Pereira inicia um processo de formação de nova sociedade. A parceria que promove com um proprietário de Agodim, freguesia de Colmeias, concelho de Pombal, não será muito precisa e clara numa primeira fase, pois não dura mais do que vinte cinco dias, passando-se à sua anulação para, nesse mesmo dia, se fazer uma nova escritura de constituição de sociedade.

Manuel da Silva Pereira apresenta-se como proprietário de casas, fornos, fornalhas, cómodos e mina ou filão de sulfato de cálcio, nas Picotas (freguesia de Souto da Carpalhosa), com um valor de dois contos de réis. Aparentemente este seria o valor global dos seus bens na primeira sociedade. A finalidade passava então a apresentar-se por discurso industrial mais moderno, para explorar o fabrico e venda de adubos químicos. No conjunto entrava com uma propriedade, uma mina e 2500000 réis em dinheiro, num total de 5500000 réis; o outro sócio entrava com 2000000 réis.

Estamos em presença de um empreendimento, com o investimento de um capital muito significativo (7 contos e 500000 réis), que difere substancialmente do valor médio para o período, nesta área económica. Apesar de tudo, a sede apresentava-se com carácter doméstico: era em casa de Manuel Silva Pereira.

Era salvaguardado o preço a praticar sobre o produto na loja (5\% de redução), que Manuel da Silva Pereira mantinha na Ortigosa. Esta informação clarifica a origem de alguns dos investimentos feitos até então por este fabricante: o comércio dinamizava e apresentava-se como actividade paralela e complementar da indústria local.

Quando se volta a formalizar a sociedade, o conteúdo deste segundo texto pouco difere, relativamente ao primeiro: baixa de $4 \%$ para $3 \%$ o lucro de vendas para o administrador - Manuel da Silva Pereira - que, entretanto, passa a cobrar 4000 réis anuais pelo arrendamento de instalações. 
Dez anos volvidos, e esse era o período previsto, dissolve-se a sociedade, dividindo-se os lucros: 100000 réis para o proprietário de Agodim, 250000 réis para o industrial da Ortigosa.

\subsection{A fase de fundamentação do poder económico: de empresário a prestamista}

Acompanhando a actividade notarial da cidade, entre 1888 e 1914, constata-se que Manuel da Silva Pereira encontrou uma outra actividade, também ela lucrativa, de investimentos de capital através de empréstimos a juros.

Não nos sendo permitido avaliar localmente a carência de moeda que se fazia sentir, por não ser efectivamente este o âmbito temático proposto, não se quis, todavia, deixar de colher informações que poderiam complementar dados que seleccionámos, com a finalidade de conhecer a formação do tecido empresarial da região de Leiria. Foi então nesta perspectiva que acompanhámos a evolução da actividade prestamista desenvolvida por Manuel da Silva Pereira.

Depois de Fevereiro de 1904, professores, proprietários, agricultores, entre outros, vão recorrer, por motivos vários, ao industrial da Ortigosa, no sentido de, a troco do pagamento de um juro, que oscilou entre $6,5 \%$ e $8 \%$, poderem aceder à moeda. Os credores provinham da própria povoação da Ortigosa ou de outras freguesias de Souto da Carpalhosa, mas apresentaram-se também residentes na cidade de Leiria, nos Milagres, em Regueira de Pontes e Alcaidaria.

À inicial actividade de proprietário agrícola foi-se associando a de comerciante, a que se juntou a de industrial e, finalmente, a de prestamista, cumprindo um percurso que, de alguma forma, correspondia ao seu perfil de homem de iniciativa, atento à realidade económica, local e nacional.

\subsection{A conquista de estatuto social}

Ao longo de pouco mais de quatro décadas acompanhámos o percurso económico, mas também social deste destacado interveniente na vida da região.

Manuel da Silva Pereira foi conquistando o respeito que transparecia através do rígido, lacónico e formal texto elaborado pelos tabeliães da cidade de Leiria. Começou por ser identificado, a exemplo de tantos outros, como 
proprietário. Era-o, de facto, como senhor de algumas terras na sua freguesia de naturalidade.

O património foi crescendo, tal como a sua actividade, que o leva a abrir um estabelecimento comercial de múltipla oferta, igual a muitos outros que conhecemos para a época, em centros mais ou menos populosos. Passa alguns anos depois a ser qualificado como proprietário e comerciante, a que rapidamente se associa a designação de industrial. Quando o encontramos a acompanhar a redacção do último dos documentos notariais da sua responsabilidade, exactamente o seu testamento, escrito em sua casa, onde o tabelião se deslocara por se tratar de pessoa poderosa, já palmilhara um longo percurso para ser dignificado com a expressão Excelentíssimo senhor Manuel da Silva Pereira.

Em simultâneo, fomos conhecendo melhor esta personalidade através da imprensa local. Se a primeira presença nos jornais decorreu da sua própria iniciativa ao procurar as potencialidades, como forma de facilitar a venda do estabelecimento fabril sito no Alto do Vieiro, freguesia da Azóia, tal opção destacava-o já no mundo da economia local.

Nos primeiros anos do século XX, mais precisamente a partir de 1907, passará a constituir notícia, a ser procurado pelo jornalista que espreita os movimentos daqueles que se evidenciam entre a população. Deixa o periódico da Marinha Grande, o Autonomia, onde debutara, para ser alvo do interesse da imprensa de Leiria.

Em 2 de Novembro de 1907, o Echos do Liz dava conta do acidente que provocara numa curva da estrada perto de Leiria, "devido à demasiada velocidade com que seguia o seu automóvel, sendo vítima o Sr. Dr. Acácio Pereira da Costa e esposa que se dirigiam de carro para esta localidade". Como homem de bem, condutor e proprietário raro de veículo automóvel, tal como o médico da cidade, "imediatamente se prontificou a indemnizar os prejuízos causados".

Em resposta à notícia vinda a lume no jornal mais importante da região, o Leiria Ilustrada, em que era claramente citado o seu poder interventivo na freguesia do Souto da Carpalhosa, Manuel da Silva Pereira publicava uma carta aberta no mesmo Echos do Liz, em 31 de Julho de 1908. Aí se defendia das vozes que aludiam à sua influência eleitoral para que "uma junta sanitária desse por incapaz o cemitério da Ortigosa". Desenhava-se o perfil do cacique político que contrariava a ideologia pró republicana dos seus críticos, apostada na valorização e modernização das populações através de bens materiais que, por vezes, contrariavam a lógica da postura religiosa. Mas este fora debate antigo, ultrapassado em grande parte do país, mas não na Ortigosa, onde a implantação do seu cemitério sofreu alguns reveses. 
Será em período de alguma conturbação política, por 1914, que definitivamente passará à ribalta das atenções jornalísticas, através da contenda dos adubos, que adiante se refere.

Como desfecho desta polémica, temos definitivamente a sua pessoa, em lugar de destaque, nos interesses mundanos locais: viagens que fez a Lisboa, idas à praia da Nazaré, indisposições físicas, agradecimentos públicos a médicos que o haviam servido ... Enfim, Manuel da Silva Pereira conquistara um lugar na sociedade leiriense, fruto dum sucesso empresarial que se derramara por outros níveis da sua vida.

$\mathrm{Na}$ actualidade, ainda se encontra a memória das suas grandezas em naturais da Ortigosa, oriundos de famílias abastadas e socialmente conceituadas. Manuel da Silva Pereira morreu como sendo um, de entre eles.

\subsection{Finalmente a polémica}

Obtivemos, assim, algum conhecimento do mundo económico que envolvia as actividades de Manuel da Silva Pereira. Também Leiria e a sua região o conheciam. Saindo de um quase anonimato, devido às suas qualidades de grande activista no espaço económico local, conseguiu reunir grandes amizades e solidariedades, como também o ser alvo de inflamados ataques que vieram para a praça pública através da imprensa local.

Entre inícios de Maio de 1914 e o mesmo mês de 1915, assiste-se a um crescendo numa polémica centrada no "fabricante de adubos da Ortigosa" e no engenheiro agrónomo Adolfo Bordalo, um dos responsáveis pela agricultura do distrito de Leiria. Acabará a contenda com o elogio feito ao fabricante, em notícia de primeira página do periódico $O$ Radical, de 22 de Abril de 1915, e com o afastamento do segundo, depois de lhe ter sido movida uma sindicância, protagonizada pelo Delegado do Procurador da República. Este, em notícia datada de Maio de 1915, dá conta do prazo que os reclamantes dispõem para esclarecer "sobre a forma por que o mesmo funcionário se tem havido no desempenho dos seus deveres profissionais" ${ }^{10}$.

Entre a primeira das datas e Maio de 1915, teve lugar uma crescente agitação que envolveria os leirienses mais ligados aos sectores agrícola e comercial, mas também os agricultores da periferia urbana, com especial incidência para os da Guia e de Monte Real.

Polarizou-se também através de dois periódicos locais: o Leiria Ilustrada, apoiante fervoroso da política de Afonso Costa e de todos os que começam a empenhar-se pelo envolvimento de Portugal na I Grande Guerra; $O$ Radical, de propriedade e direcção do deputado Ribeiro de Carvalho, delegado do 
Partido Evolucionista no distrito, muito frequentemente apologético do Dr. António José de Almeida ${ }^{11}$. Ao desenvolvimento da contenda não seria estranho o facto de, em Janeiro de 1914, o engenheiro Bordalo ser presidente do Centro Democrático Leiriense... ${ }^{12}$.

A questão politizou-se por esta via, resultando o desfecho de forma adequada à conjuntura política então vivida, protagonizada por democráticos e evolucionistas.

Pelo meio, sem manifestar qualquer laivo de apoio a uns ou a outros, situara-se $O$ Mensageiro, semanário católico que inicia a sua publicação no centro do período considerado.

Quais as razões invocadas para lançar a polémica?

Parece poder utilizar-se o título da primeira notícia surgida em Maio de 1914 para, de alguma forma, encontrarmos uma explicação muito explícita: "Adubos e mixórdias. A ignorância dos agricultores favorecendo o comércio fraudulento de adubos". Como o próprio engenheiro agrónomo, Adolfo Bordalo exporia no texto, não era necessário ter ciência nem capitais para falsificar adubos e muitas eram as vozes que clamavam contra os enganos a que os camponeses eram sujeitos. Na verdade, o cumprir-se a legislação que obrigava a que nos sacos fosse estampada a composição do adubo, isso pouco significado tinha para uma camada essencialmente iletrada; principalmente, através de informação mais dificultada e engenhosa, que se apresentava sob a forma de percentagens.

O próprio Alfredo da Silva, director da Companhia União Fabril, em entrevista concedida ao Século, em 17 de Outubro de 1913, denunciara já o que se verificava neste sector, pois, segundo a sua opinião, onde quer que existisse uma mina de gesso, logo aparecia uma suposta fábrica de adubos, que procedia à mistura do gesso com fosfatos e terra. Adiantava o vazio que a legislação portuguesa apresentava para atacar este mal.

Obviamente que esta entrevista, pelos fins que permitia atingir, foi transcrita pelo Leiria Ilustrada, em Abril de 1915, com o título "Uma variante do conto vigário".

Meses antes, em 6 de Novembro de 1914, sob o título "A ganância", tinha apresentado uma notícia que em nada granjeara simpatias para o grande industrial do Barreiro, pois a CUF surgira como responsável pela subida de preços registada nos adubos, através da estratégia de açambarcamento dos produtos nobres para o respectivo fabrico.

O lançamento da questão, que colocava Manuel da Silva Pereira no centro das atenções não só dos agricultores, mas também da população em geral, foi gerado pela recusa dum comerciante de Alcobaça, José Sanches Furtado, em pagar um fornecimento de sacas de adubo, por ele produzido e vendido. As razões apresentadas baseavam-se na falta de qualidade do 
produto, face ao que se anunciava estampado na sacaria e mesmo nas facturas. Abriu-se um litígio a que não foi estranho ongenheiro Bordalo, que interfere mesmo como testemunha ${ }^{13} \mathrm{O}$ acórdão, proferido pelo juiz, obrigará Sanches Furtado a proceder ao pagamento da dívida ao fabricante da Ortigosa.

Objectivamente era posta em causa a composição dos adubos produzidos, vendidos e distribuídos a partir da Ortigosa: $0,12 \%$ de ácido fosfórico, valor aproximado ao de terrenos basálticos da região de Lisboa.

Partindo desta análise ao conteúdo dos sacos do adubo de designação "Leiriense", vendido também nos concelhos de Pombal e Alcobaça, são tiradas ilações através do jornal sobre o preço real e o praticado pelo fabricante, para concluir que era vendido a 13000 vezes mais do que deveria custar, valendo menos do que o preço do próprio saco que o continha.

À denúncia, feita pelo engenheiro agrónomo sobre a composição dos adubos, juntava-se sempre uma feição pedagógica, alertando os camponeses para a diversidade de adubos que deveriam ser considerados, em função dos terrenos e respectivas culturas. Mas também havia uma intenção política em toda esta campanha, que passamos a compreender claramente através do título de uma secção, na qual se publicavam artigos sobre a temática, que se prolongará por diversas semanas, intitulada "Processos herdados da monarquia". Concluiremos que não está em causa um monárquico, mas sim um evolucionista.

Uma verdadeira contenda tem lugar no momento em que os dois opositores se encontram, exactamente numa manhã de Domingo, quando Manuel da Silva Pereira entrava na redacção do jornal $O$ Radical. Este publicara, dias antes, um artigo assinado pelo industrial dos adubos, insurgindo-se contra o engenheiro Adolfo Bordalo. Este segue-o dentro do edifício do jornal e, a partir daqui, temos duas versões distintas sobre o que se desenvolveu então. As perspectivas são incluídas nos artigos que cada jornal redigirá sobre o mesmo assunto, qualquer um da responsabilidade dos respectivos intervenientes. Trocam-se os epítetos, mudam-se espaços e percursos na cidade. A realidade passava a conter duas verdades.

A partir daqui, a polémica torna-se mais violenta até que, pouco antes do afastamento do engenheiro Adolfo Bordalo, $O$ Radical mostra claramente $o$ tom de vitória, sob o título "O pasquim":

O nosso honrado e velho amigo Manuel da Silva Pereira, homem de carácter que todo o distrito respeita e considera, continua a ser anavalhado pelo pasquim do senhor Padre Mateus . 
É de orgulho ser atacado e caluniado por essa desprezivel escória. Aquilo não é um jornal: é um cano de esgoto. Aquilo não é o órgão de um partido: é um vasadoiro imundo, uma cloaca pública. ${ }^{14}$

\section{A CONSOLIDAÇÃO DO PODER}

\subsection{O casamento como forma de estabilização social, mas também económica}

Manuel da Silva Pereira morreu em 30 de Agosto de 1929, sem deixar filhos "numa casa do lugar da Ortigosa, de amolecimento cerebral, com sessenta e três anos de idade, de profissão proprietário"15.

Como fizera o seu testamento alguns anos antes, a transmissão dos seus bens ficara por si definida e salvaguardada. No entanto, sendo herdeira maioritária a sobrinha e afilhada, Adelaide, que contava então quinze anos, procedeu-se a inventário orfanológico.

A fortuna construída ao longo da sua vida, que ascendia a cerca de 347 contos, dividia-se entre a viúva, a irmã do falecido, Maria Pereira, e os seus cinco filhos. Privilegiava a sobrinha, por via de sua esposa, que era afilhada do casal e que por ele fora criada.

Casara, em primeiras e únicas núpcias aos 34 anos de idade, com D. Adelaide Pedrosa, de 27 anos, natural da vizinha freguesia de Carvide. Um casamento tardio para ambos os nubentes, que se apresentaram em situações de riqueza perfeitamente desiguais, aquando da redacção do contrato antenupcial, celebrado em Abril de 1900 : enquanto ele declarava propriedades no valor de pouco mais de 10 contos de réis, a noiva não levava "bens alguns para o casal, porque por enquanto os não possue". O enlace ocorreu nesse mesmo ano "com inteira separação de bens e comunhão de adquiridos" $" 16$.

Ao longo de 29 anos, o casal construiu uma fortuna de mais de 300 contos, partindo da existência de terras de semeadura, vinhas e baldios, mas, sobretudo, "um casal no lugar da Ortigosa, composto de casas de habitação com seus commodos onde se acha estabelecida uma fábrica de adubos chimicos e de terra de semeadura com poço de água", avaliado em 7500000 réis, bem como "uma propriedade na Ortigosa com uma casa onde existe um estabelecimento de fazendas com adega pegada, casa de lagar, uma eira de cal e um bocado de terra", com o valor de 350000 réis $^{17}$. Estes bens constituíram o fundamento de todo o sucesso empresarial de Manuel da Silva Pereira, que manteve até ao final da sua vida. 
Sem conhecer o nascimento de qualquer filho, cedo elegeu o seu continuador, ou melhor, a sobrinha directa de sua esposa, simultaneamente afilhada, que com eles passa a viver e que era portadora do mesmo nome da madrinha - Adelaide. Ao redigir o seu testamento, três anos antes de vir a falecer, beneficia-a naturalmente, face aos restantes sobrinhos, com a condição desta se manter na sua companhia. Será Adelaide Correia Pedrosa que se tornará proprietária da fábrica de adubos, encerrando o percurso de sucesso do homem da Ortigosa.

Das muitas lutas travadas e ganhas na defesa da empresa que fez nascer, reconhece-se que a ausência de filhos o obrigou a encaminhá-la para a família da que se tornara sua companheira conjugal.

\subsection{A atenção às novas oportunidades do mercado}

O ano de 1917 assistiu ao investimento deste empresário num novo sector: o da exploração de águas minero-medicinais. Em Janeiro desse ano, o Diário do Governo regista a concessão de licença de exploração da nascente das caldas de Monte Real a Silva Pereira ${ }^{18}$.

Apresentou então ao Ministério do Fomento uma planta das obras que pretendia realizar, como declarou numa acção de expropriação que foi obrigado a mover aos proprietários de uns terrenos que lhe eram necessários "para abertura da Avenida que da estrada distrital conduz à nascente"19. A resolução será encontrada amigavelmente em Fevereiro do mesmo ano, quando os expropriados se apresentaram a aceitar o acordo proposto pelo expropriante.

O estabelecimento balnear, em total estado de ruína, fora adquirido em hasta pública, à Câmara Municipal de Leiria, que decidira esta venda em 1916. Manuel da Silva Pereira "comprou os terrenos em volta da nascente, rasgou a Avenida das termas, construiu um bom balneário"20.

Oferecer serviços de utilidade médica, só por si, não o satisfazia. Daí que a sua visão empresarial o tivesse levado mais longe: vai munir Monte Real duma unidade hoteleira que pudesse concorrer com outras estâncias similares. Promovendo o seu novo empreendimento, fez por todo o país propaganda às propriedades das águas, a que associava a beleza da região.

As termas passaram a oferecer um Hotel bem apetrechado a toda uma população que aqui procurava saúde e repouso. A povoação passava a ter boas razões para se mostrar agradecida a Manuel da Silva Pereira, pois Monte Real continuava a ser publicitada com frequência nos jornais da região, promovendo um "turismo termal" em fase crescente. 
Em 1925 faz doação do complexo a um sobrinho, Olímpio Duarte Alves, que o manteve em fase de bem sucedida exploração até aos anos $50^{21}$.

\section{O RELACIONAMENTO COM OS PARCEIROS ECONÓMICOS}

Se foi notável a presença de Manuel da Silva Pereira nos cartórios notariais de Leiria, o mesmo se poderá constatar, relativamente à frequência com que foi interveniente em causas judiciais no tribunal da cidade. $O$ primeiro acto notarial datara de Janeiro de 1888 e o seu correspondente na barra da justiça ocorreu em Agosto de 1899.

Em causa apresentava-se o desejo de vender o seu quinhão na sociedade constituída três anos antes, para exploração de um filão de gesso nas Picotas, com a durabilidade, então prevista, de dezanove anos. Entrara com um valor "até 30000 réis para as despesas de exploração e condução até à estação do caminho de ferro de Monte Real",22, tal como o seu sócio, Manuel Oliveira Jordão, um proprietário de Alcaidaria.

Se o processo se inicia com a classificação de "Autos cíveis de notificação para preferências" ${ }^{23}$, anteve-se a impossibilidade de se ter chegado a qualquer acordo amigável numa causa aparentemente tão pacífica. $\mathrm{O}$ acordo anterior que Silva Pereira fizera com o pai, que se apresentava a oferecer-lhe 300000 réis pelo referido quinhão, poderá suscitar a dúvida sobre uma estratégia familiar de valorizar excessivamente a sua parte na sociedade. Em virtude da audiência marcada a Oliveira Jordão ter falhado, por ocorrer a um feriado, iniciava-se a complexização de todo o processo: contra Manuel da Silva Pereira passava a ser movido um agravo, por parte de Oliveira Jordão.

Antes de subir ao Tribunal de Relação de Lisboa, escrevia o Juiz de Direito um desabafo: "insistindo em tornar contencioso um processo que de sua natureza não admite nenhuma impugnação",24. Cerca de um ano volvido, é dado como concluído o processo com o pagamento das custas à responsabilidade de Silva Pereira. Perdera a causa ...

Mas ainda estes autos não haviam conhecido epílogo e já o mesmo Oliveira Jordão o processava por não prestar contas da exploração de gesso, retirado da mina nas Picotas ${ }^{25}$. Ao longo de cinco anos produzir-se-ão argumentos e contra-argumentos, provas e contraprovas que servirão para clarificar a reputação económica e social dos opositores, bem como a lucidez jurídica de dois ilustres advogados: João Correia Mateus e Afonso Xavier Lopes Vieira. 
Novamente Manuel da Silva Pereira ficava com o encargo do pagamento dos custos judiciais, depois de ter manifestado o desejo de pôr termo à contenda. Afinal, Oliveira Jordão também era uma personalidade destacada na sociedade e na praça leiriense.

Já em 1914 reaparece o proprietário, comerciante e industrial da Ortigosa nos corredores do tribunal de Leiria. Tratava-se do processo anteriormente referido.

Corria o mês de Abril e a imprensa de Leiria criava a atmosfera da polémica que a produção de adubos suscitava, como já vimos. $\mathrm{Na}$ realidade, o comerciante alcobacense era acusado por Manuel da Silva Pereira de não ter pago a totalidade de uma remessa de adubos que recebera da Ortigosa, para venda no seu estabelecimento. Pelo meio ficara a recusa de aceitação de uma letra creditada à agência do Banco de Portugal, em Leiria.

O processo avança com o depoimento de testemunhas que são questionadas sobre a qualidade do produto ensacado na fábrica de adubos da Ortigosa.

Segue-se igualmente um conjunto de provas às dosagens de fosfatos que integram o fertilizante, colocando-nos perante um quadro de saberes técnicos que ultrapassam largamente a vulgaridade de qualquer testemunha. Entre elas contava-se, como era previsível, o engenheiro agrónomo Adolfo Bordalo. Aliás, os textos produzidos pela defesa do fabricante da Ortigosa ou pela do comerciante de Alcobaça atestavam que já não era a recusa de pagamento que estava em causa, mas sim a qualidade dos próprios adubos.

Numa antevisão do que será o desfecho da questão que oporá Manuel da Silva Pereira ao engenheiro Bordalo, a sentença obrigou José Sanches Furtado a pagar a dívida ao produtor de adubos e os respectivos custos de tribunal.

Seguem-se anos de acalmia no que respeita a qualquer tipo de conflito com parceiros do mundo dos negócios, saboreando a grande vitória judicial sobre o fabrico de fertilizantes químicos.

Em 1921 é aberta uma nova questão, que tem como centro as minas de gesso e a fábrica de adubos. O industrial era acusado de não ter pago uma letra de 50 contos, valor do sinal por si aceite da venda daqueles bens a uma sociedade para exploração de adubos, liderada por uma instituiçãó bancária em formação - o Banco Nacional Agrícola ${ }^{26}$. Esta associara alguns nomes importantes da vida económica da região, entre os quais Raul Tomé Feteira, de Vieira de Leiria, e Joaquim Matias Sobrinho, da Marinha Grande.

$O$ processo apresentado relatava uma situação em que os prazos de concretização do negócio, por motivos alheios ao próprio Silva Pereira, não 
foram cumpridos: o banco não se formou, a sociedade não se concretizou, a venda não se consumou.

Paralelamente às actividades no comércio e na indústria, decorria a sua actividade ligada ao crédito. Foi o empréstimo em dinheiro que motivou as duas últimas causas judiciais em que se envolveu. A primeira ocorreu em Maio de 1925 e permitiu-lhe reaver o montante de $33500 \$ 00$, da parte de uma viúva da alta sociedade leiriense ${ }^{27}$. A segunda, do ano seguinte, permitiu-lhe enriquecer o seu património imobiliário, à custa do arresto de propriedades no lugar do Sargaçal, freguesia do Souto da Carpalhosa, a troco de uma dívida que não fora solvida, no valor de $1100 \$ 00$.

Estávamos em 1926, ano em que Manuel da Silva Pereira redigiu o seu testamento. Atingia a plenitude da fortuna e decidira intervir na sua transmissão.

\section{A PREPARAÇÃO DA TRANSMISSÃO DE TESTEMUNHO: O TESTAMENTO E A SUA RELAÇÃO COM A VIDA ATRAVÉS DA MORTE}

Em Julho de 1926, o casal Silva Pereira recebeu, na sua casa da Ortigosa, o notário José Falcão de Gouveia. Não se tratando de uma situação extrema que o impossibilitasse da deslocação ao cartório de Leiria, estamos perante um tratamento diferencial.

Acerca da forma de suprir a não existência de filhos, já anteriormente demos conta: para além da mulher, irmã e sobrinhos eram escolhidos os herdeiros ${ }^{28}$.

À eleita, a sobrinha e afilhada, era pedida a companhia e o cuidado. Para além da casa de habitação, respectivo recheio, terras e vinhas, Adelaide Correia Pedrosa tornar-se-ia proprietária da fábrica de adubos químicos.

Mas Manuel da Silva Pereira pretendeu alargar o leque daqueles que poderiam vir a cultivar a sua memória, através da atribuição de bens materiais. Assim, cada criado da casa que estivesse ao serviço, à data do seu falecimento, receberia $250 \$ 00$. Às crianças da freguesia legava $50 \$ 00$ anuais para que fosse paga "uma catequista pobre, religiosa, honesta e que case religiosamente"29. Ao pároco de Souto da Carpalhosa seriam entregues 2 contos "para com o seu rendimento fazer uma festa anual ao Santíssimo Sacramento" $"$. Contemplava ainda os pobres, presentes ao seu último ofício, com $200 \$ 00$ de esmola. 
Perpetuava-se, desta forma, a memória do conterrâneo ilustre, que tão repetidamente trouxera a pequena povoação ao palco dos acontecimentos regionais.

Não esquecia, nesta intenção de fazer perpetuar a sua presença, de estipular o número de missas que, para além de serem rezadas por si e pelos seus familiares mais próximos, deveriam ser ditas "por alma das pessoas com quem teve negócios". Apaziguava-se definitivamente com todos aqueles que, por motivos diversos, enfrentara no seu quotidiano de homem económico e socialmente activo.

Formalizava também o modo de ser recordado após a sua morte, como benemérito e homem de bem, de que a freguesia do Souto da Carpalhosa se poderia orgulhar.

\section{PARA CONCLUIR ...}

Estamos ainda perante o empresário que localmente já ganhou um espaço económico amplamente reconhecido, mas que, ao integrar uma economia mais alargada, se encontra numa primeira fase da evolução. $\mathrm{Na}$ verdade, pertenceu ao grupo empresarial de pequenas dimensões, fazendo na sua pessoa a interseç̧ão das coordenadas que constituem os elementos da economia empresarial - a propriedade e a direç̧ão.

Se considerarmos a carreira-tipo de Manuel da Silva Pereira, estaremos, sem sombra de dúvida, perante o empresário na verdadeira acepção da palavra: criou e fundou a sua própria empresa, arriscando na inovação as potencialidades dum capital seguro, decorrente do sector comercial, investido numa actividade incerta, sob o ponto de vista do lucro, e que os anos de 1914 e 1915 vieram demonstrar necessitar duma defesa enérgica.

Rompeu o cerco de homem desconhecido, tornando-se um elemento socialmente destacado. Integrou uma elite regional, à custa das suas qualidades empreendedoras. Esforçou-se por não ser ignorado nem esquecido. Pensamos que o conseguiu plenamente.

Relativamente às fontes utilizadas, a imprensa local permitiu-nos o acesso a uma informação sobre personalidades que, pelas suas funções, fizeram transpirar os seus actos para o domínio do público. Através dela, fomos conhecendo episódios da vida de uma cidade em expansão económica, à medida da conjuntura dos inícios da República. Mas, e principalmente, fomos colocados perante acontecimentos de âmbito restrito que nos permitem uma melhor compreensão de movimentos mais complexos e alargados, do ponto de vista histórico. O jornal deu mais vida e colorido ao 
documento notarial e judicial. $\mathrm{O}$ jornal deu corpo e imagem aos adversários das contendas judiciais.

\section{NOTAS}

**A temática abordada neste texto insere-se num trabalho de doutoramento, a apresentar à Faculdade de Letras da Universidade de Coimbra, sobre a formação do tecido empresarial da região de Leiria.

1 Sobre as diferentes acepções do vocábulo, vide, por exemplo, o estudo de Maria Filomena Mónica, "Capitalistas e industriais (1870-1914)", Análise Social, vol. XXIII (99), 1987, p. 819-863. Também sobre esta diferenciação se pronunciou J. M. Amado Mendes, A área económica de Coimbra, p. 1-4; 16-25.

${ }^{2}$ A mesma autora refere para Inglaterra uma divulgação do termo industrial a partir de 1860. A anterior designação de manufacturer aproxima-se da utilizada entre nós: fabricante. Ibidem, p. 821 .

${ }^{3}$ Cfr. Jaime Reis, entre outros. Deste autor, vide “ A industrialização num país de desenvolvimento lento e tardio: Portugal, 1870-1913”, Análise Social, vol. XXIII (96), 1987, p. 207-227. Opinião diferente é defendida por J. Borges de Macedo, nomeadamente no art". "Indústria", incluído na Enciclopédia Verbo.

${ }^{4}$ Entre outras, são referidas a Companhia de Ferro e Carvão de Portugal, a Sociedade Exploradora das Regiões Petrolíferas de Portugal, a Sociedade de Zonas de Petróleo em Portugal.

${ }^{5}$ Cfr. João Cabral, Anais do Município de Leiria, vol. II, p. 96-122.

${ }^{6} \mathrm{~W}$. Plum, O empresário, personagem marginalizado na sociedade industrial, p. 16-17.

(Aqui, como nas restantes citações, actualizámos a ortografia).

${ }^{7}$ Arquivo Distrital de Leiria (A.D.L.), Livro notarial 13 I-1, fls. 46-V. Não deixava de ser um qualificativo ainda pouco consistente, pois no mês seguinte já era apresentado como negociante (Livro notarial $10 \mathrm{I}-3$, fls.79-v.

${ }^{8}$ Autonomia, $\mathrm{n}^{\circ} 91$, de 5 de Julho de 1891.

${ }^{9}$ A.D.L, Livro notarial $10 \mathrm{C}-13$, fls. $40 \mathrm{~V}-41$. Em documento judicial avulso, datado de 25 de Setembro de 1895, era identificada a empresa como Fabrica de Phósphoros Progresso. Aludia-se então à necessidade de um tribunal arbitral para julgar da expropriação de que era alvo. Não se tornará a encontrar qualquer referência directa a esta fábrica, podendo de facto ter desaparecido ou sido substituída pelo interesse que os adubos passam então a suscitar.

${ }^{10}$ O Mensageiro, número 32, de 12 de Maio de 1915.

${ }^{11}$ Leiria Ilustrada, de 24 de Janeiro de 1914. Assina, então, a convocatória para uma reunião.

${ }^{12}$ O número 1 de $O$ Radical é de 7 de Outubro de 1914

13 Arquivo Histórico do Tribunal Judicial de Leiria (A.H.T.J.L.), Acção ordinária

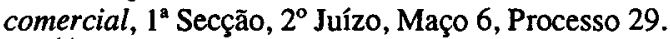

${ }^{14}$ O Radical, número 213, 22 de Abril de 1915.

${ }^{15}$ A.H.T.J.L. - Inventário Orfanológico, $1^{\text {a }}$ Secção, $1^{\circ}$ Juízo, Maço 22, Processo 8. 
${ }^{16}$ A.D.L., notário Carlos Rufino Coelho Vale, em 12 de Abril de 1900, Livro notarial 103, fls. 18-19.

${ }^{17}$ Ibidem.

${ }^{18}$ Diário do Governo, $\mathrm{n}^{\circ} 4$, II série, 5 de Janeiro de 1917.

19 A.H.T.J.L. - Autos de expropriação por utilidade pública, $2^{\mathrm{a}} \mathrm{Secção,} 1^{\circ}$ Juízo, Maço 16, Processo 11.

${ }^{20}$ Isidro P. de Brito, Monte Real, terra histórica ontem e hoje, p. 53-54.

${ }^{21} \mathrm{Ibidem}$. Sobre este sobrinho, não se lhe encontra qualquer referência, quer no texto do testamento redigido em 1926, quer no inventário orfanológico a que se procedeu em 1929. Olímpio Duarte Alves perpetuou o seu nome através de duas monografias, que redigiu sobre Monte Real: Monte Real no passado e no presente e monte Real-costumes e tradições das terras de Ulmar, ambas edição do autor, de 1955 e 1963, respectivamente.

${ }_{22}$ A.D.L. - Livro notarial 10 I-12, fl.7-v, de 25 de Agosto de 1896.

${ }^{23}$ A.H.T.J.L. - $1^{\text {a }}$ Secção, $1^{\circ}$ Juízo, Maço 11, Processo 4.

${ }^{24}$ Ibidem, fl. 24.

${ }^{25}$ A.H.T.J.L. - Autos civeis de apelação, $2^{\mathrm{a}}$ Secção, $1^{\circ}$ Juízo, Maço 32, Processo 22.

${ }_{26}^{26}$ A.H.T.J.L. - Agravo Comercial, $2^{\mathrm{a}}$ Secção, $1^{\circ}$ Juízo, Maço 2, Processo 27.

${ }^{27}$ A.H.T.J.L. - Autos cíveis de execução hipotecária, $1^{\circ}$ Secção, $1^{\circ}$ Juízo, Maço 16 , Processo 46.

${ }_{28}^{28}$ A.D.L. - Livro notarial 17, fl.34-35.

${ }^{29}$ Ibidem, fl. $34 \mathrm{~V}$.

${ }^{30}$ Idem, idem.

\section{FONTES}

\section{Biblioteca Pública e Arquivo Distrital de Leiria:}

Livros notariais, cartórios de Leiria, entre 1888 e 1915

Jornais (anos 1891-1915):

Distrito de Leiria

Echos do Liz

Leiria Ilustrada

Liz

O Mensageiro

O Radical

Biblioteca Nacional:

Autonomia (Jomal da Marinha Grande)

Arquivo Histórico da Câmara Municipal de Leiria:

Livros de registo de minas da Câmara Municipal de Leiria (1872-1914) 


\section{Arquivo Histórico do Tribunal Judicial de Leiria:}

Processos criminais; personalidades do mundo empresarial

Inventários Orfanológicos

\section{BIBLIOGRAFIA}

BERGERON, Louis (1975), Banquiers, négociants et manufacturies parisiens, Atel. Reprod. Theses, Université de Lille III.

BORDALO, Adolfo (1915), Exposição e crítica dos condenáveis processos adoptados por Manuel da Silva Pereira, Tipogr. Leiriense, Leiria.

BRITO, Isidro P. (1991), Monte Real, terra histórica ontem e hoje, Região de Turismo de Leiria.

BOURDELAIS, Patrice (1984), "L'industrialisation et ses mobilités", Annales E.S.C., n5, Sept.-Octobre, pp.1009-1019.

CABRAL, João (1975), Anais do Município de Leiria, 2 vols., ed. Câmara Municipal de Leiria.

CABRAL, M. Villaverde (1988), Portugal na alvorada do século XX. Forças sociais, poder político e crescimento económico de 1890 a 1914, Edit. Presença, Lisboa.

CORREIA, Francisco A. (1927), A evolução económica e a crise social, Instituto Superior Comércio de Lisboa.

CUSTÓDIO, Jorge (coord.) (1994), Empresariado português. Uma abordagem às suas realizações, Associação Industrial Portuense, Porto.

DRUCKER, Peter F. (1986), Inovação e Gestão. Uma nova concepção de estratégia de empresa, Editorial Presença, Lisboa.

FONSECA, Hélder Adegar (1995), "As elites económicas alentejanas, 1850-1870: anatomia social e empresarial", Análise Social, vol. XXXI, n 136-137, p. 711-748.

JUSTINO, David (1988), A formação do espaço económico nacional, 2 vols., Edit. Veja, Lisboa.

MARKLER, Harry M. (1969), A "elite" industrial portuguesa, Instituto Gulbenkian de Ciência, Centro Economia e Finanças, Lisboa. 
MENDES, J. M. Amado (1984), A área económica de Coimbra. Estrutura e desenvolvimento industrial, 1867-1927, C.C.R.C., Coimbra.

“ (1990), "Bloqueios à inovação no tecido empresarial português em finais do século XIX: achegas para o seu estudo", Revista de História, C.História Universidade do Porto, vol. X, p.193-201.

“ (1992), "O contributo da biografia para o estudo das élites locais: alguns exemplos", Análise Social, XXVII, n 116-117, p. 357-365.

“ (1995), "Sucesso e inovação no mundo empresarial. Perspectiva histórica", Gestão e Desenvolvimento; $\mathrm{n}^{\circ} 4$, Universidade Católica Portuguesa, Centro Regional das Beiras, Viseu, p. 41-57.

“ (1997), "Cultura empresarial e Nova História de empresas”, Gestão e Desenvolvimento; $\mathrm{n}^{\circ}$ 5-6, Universidade Católica Portuguesa, Centro Regional das Beiras, Viseu, p. 141-158.

MILLS, C. Wright (1957), La elite del poder, Fond. de Cultura Económica, Buenos Aires. MÓNICA, Maria Filomena (1987), "Capitalistas e industriais (1870-1914)", Análise Social, vol. XXIII (99), p. 819-863.

PEDREIRA, J. Miguel (1986), Indústria e atraso económico em Portugal (1800-1825), dissertação de mestrado em Sociologia e Economia Históricas, Faculdade Ciências Sociais e Humanas, Universidade Nova, Lisboa, (policopiado).

PEREIRA, M. Halpern (1983), Livre-câmbio e desenvolvimento económico, Sá da Costa Edit., Lisboa.

PLUM, Werner (1979), O empresário, personagem marginalizado na sociedade industrial, Cadernos do Instituto de Pesquisa da Fundação Friedrich Ebert, Bonn.

REIS, Jaime (1986), "A produção industrial portuguesa, 1870-1914: primeira estimativa de um índice", Análise Social, vol. XXII (94), p. 903-928.

“ (1987), "A industrialização num país de desenvolvimento lento e tardio: Portugal, 1870-1913" Análise Social, vol. XXIII (96), p. 207-227.

REIS, José (1987), "Os espaços da industrialização - notas sobre a regulação macroeconómica e o nível local”, revista Crítica de Ciências Sociais, $\mathrm{n}^{\circ} 22$, Abril.

SCHUMPETER, J. (1961), Capitalismo, socialismo y democracia, Aguillar, $2^{\mathrm{a}}$ ed., Buenos Aires.

SERRÃO, Joel (1980), Temas Oitocentistas. Para a História de Portugal no século passado, 2 vols., Livros Horizonte, Lisboa.

SOMBART, Werner (1926), Le Bourgeois, Payot, Paris.

“ (1932), L'apogée du capitalisme, 2 vols., Payot, Paris.

WEBER, Max (1983), A ética protestante e o espírito do capitalismo, Edit.Presença, col. "Biblioteca de Textos Universitários", Lisboa. 